\title{
Redes de apoyo social, un cobijo resiliente para familias desplazadas con integrantes desaparecidos
}

\author{
Karla Salazar Serna \\ Universidad Autónoma de Tamaulipas. Unidad Académica de Trabajo Social \\ y Desarrollo Humano \\ Orcid: <https://orcid.org/0000-0003-4101-126X> \\ ksalazar@uat.edu.mx
}

Recepción: 11-12-2020

Aceptación: 16-06-2021

Publicación: 13-01-2022

\section{Resumen}

México sufre una crisis humanitaria en la que se han registrado más de 95.000 personas desaparecidas en los últimos 15 años. Las familias que tienen desaparecidos no solo padecen las numerosas implicaciones de una pérdida ambigua, sino que también lidian con otras vejaciones, como el desplazamiento forzado. No obstante, existen vías que permiten sobrellevar la adversidad y lograr sobreponerse a través de procesos de reconstrucción edificados sobre la resiliencia. El presente análisis se deriva de una investigación de corte cualitativo basada en entrevistas en profundidad y observación participante que tuvo como objeto indagar sobre las alternativas que tienen las familias de personas desaparecidas que han sufrido el desplazamiento forzado interno. Reconociendo la dimensión relacional de la resiliencia, se pretendió conocer cuáles son las redes de apoyo social con las que cuentan. Entre los hallazgos más relevantes, se encuentran los siguientes: las familias se concentran más en las acciones de búsqueda de sus familiares que en establecerse en sus nuevos lugares de asentamiento; las redes de apoyo social más efectivas para colaborar en su salvaguarda están construidas con familias que también buscan a sus desaparecidos; los procesos de resiliencia son edificados, en gran medida, a través de la interacción y la generación de vínculos afectivos con integrantes de los colectivos y durante las brigadas de búsqueda. Con este análisis, se concluye que, si bien la violencia tiene un poder desarticulador, este no es determinante sobre la vida de las familias al existir la posibilidad resiliente de reconstruirse a través de las redes de apoyo social.

Palabras clave: desapariciones; desplazamiento interno forzado; redes de apoyo social; resiliencia; violencia 
Abstract. Social support networks, a resilient shelter for displaced families with missing members

Mexico suffers a humanitarian crisis because more than 95 thousand people have disappeared in the last 15 years. Families with missing relatives not only suffer many implications related with ambiguous loss, also deal with other problematics such as forced displacement. However, there are ways that make it possible to cope with adversity and overcome through reconstruction processes built on resilience. This analysis is derived from a qualitative research, based on in-depth interviews and participant observation, the aimed was investigate the alternatives that families with relatives disappeared who have suffered internal forced displacement have, recognizing the relational dimension of the resilience, it was intended find out the social support networks that they have. Among the most relevant findings are: families are more focused on searching for their relatives than on settling down in their new places of settlement; the most effective social support networks to collaborate in their safeguarding are built with families who also search for their disappeared; resilience processes are built primordially through the interaction and generation of affective bonds with members of the collectives and during searching actions. Through this analysis, it is concluded that although violence has a disarticulating power, it is not decisive on the lives of families as there is a resilient possibility of rebuilding through social support networks.

Keywords: disappearance; forced internal displacement; social support network; resilience; violence

\author{
Sumario \\ 1. Introducción 5. Discusión \\ 2. Marco teórico 6. Conclusiones \\ 3. Método Agradecimientos \\ 4. Resultados Referencias bibliográficas
}

«El trauma ha hecho añicos la personalidad anterior, y cuando nadie reúne los pedazos para frenar su dispersión, el sujeto queda muerto y no vuelve bien a la vida"

Boris Cyrulnik (2006: 21)

\title{
1. Introducción
}

En México los escenarios de violencia se han multiplicado a partir de la implementación de las políticas de seguridad bajo el sexenio del expresidente Felipe Calderón Hinojosa y por la continuidad que ejerció su sucesor, Enrique Peña Nieto (Gutiérrez, 2016; Trejo y Ley, 2016). Los actos de violencia son visibles a través de la proliferación del fenómeno de desaparición forzada cometida por particulares. Hasta el mes de noviembre del 2021 el registro era de 95.121 personas desaparecidas (Registro Nacional de Personas Desaparecidas y no Localizadas). También es importante señalar que existen más de 4.513 fosas 
clandestinas (Subsecretaría de Derechos Humanos, Población y Migración) y más de 52.000 cuerpos sin identificar en servicios forenses (Movimiento por Nuestros Desaparecidos en México).

Junto con estas cifras, se suma el fenómeno del desplazamiento. De acuerdo con la Comisión Mexicana de Defensa y Promoción de los Derechos Humanos, ${ }^{1}$ del 2006 al 2019 se contabilizaron (según el registro históricoacumulativo) 346.945 personas desplazadas internamente debido a la violencia. El último conteo detallado que realizó este organismo fue el correspondiente al año 2017. Las regiones con más casos registrados fueron las siguientes: 6.090, Chiapas; 5.948, Guerrero; 2.967, Sinaloa. Según Díaz y Romo (2019), en los años recientes, el desplazamiento forzado en México tiene un estrecho vínculo con la violencia asociada al narcotráfico y el crimen organizado. Además, no se puede contar con un registro certero de personas desplazadas por esta violencia debido a que evitan dejar rastro y se resguardan bajo el anonimato.

Esta violencia genera diversos efectos sobre las familias y es difícil dimensionar sus repercusiones. Por ejemplo, en los casos de desaparición, los procesos de dolor, desesperanza, angustia y frustración se van acumulando con los años hasta no saber sobre el paradero de la persona desaparecida (Stornaiuolo et al., 2007; Gatti, 2011). Es importante señalar que la desaparición genera una pérdida ambigua en familiares y allegados, ya que las personas perciben al desaparecido ausente físicamente, pero presente psicológicamente (Cabodevilla, 2007). Esta situación conlleva asumir la existencia de un profundo dolor, donde sentimientos de culpa y angustia se acentúan y evidencian de forma particular, pues la incógnita sobre el fin de su ser querido es una cuestión tormentosa (Delgado, 2014). Para Bezanilla y Miranda (2014), en aquellas familias donde ha ocurrido la desaparición forzada de uno o más integrantes, se han advertido procesos de "duelo alterados», los cuales se caracterizan por la presencia constante de incertidumbre en los que deriva el trauma, ya que la familia queda "suspendida» en un momento, con la pregunta constante sobre el paradero de la persona ausente.

Así pues, el desplazamiento forzado interno ${ }^{2}$ genera efectos que inciden sobre el bienestar de las personas, trastornos en la salud física y en la salud mental; la economía se ve disminuida, las redes de apoyo coartadas, el desarrollo personal interrumpido y en algunos casos se manifiestan afectaciones en las identidades cuando existe despojo territorial, discriminación, exclusión, quebrantamiento de vínculos culturales, vulnerabilidad social, marginación y precariedad (Marinis, 2017; Mercado, 2013; 2016; 2018; Salazar y Álvarez,

1. Véase el informe Episodios de desplazamiento interno forzado masivo en México, 2019.

2. Se reconoce el desplazamiento forzado interno como aquel donde las personas se ven forzadas u obligadas a escapar o huir de su hogar o de su lugar de residencia habitual, en particular como resultado o para evitar los efectos de un conflicto armado, de situaciones de violencia generalizada, de violaciones a los derechos humanos o de catástrofes naturales o provocadas por el ser humano, y que no han cruzado una frontera estatal internacionalmente reconocida (Comisión de Derechos Humanos de la Organización de las Naciones Unidas a través del documento Principios rectores de los desplazamientos internos). 
2018; Velázquez, 2017). De manera más puntual, Velázquez (2016; 2017) ha señalado que las personas desplazadas viven un continuo estado de vulnerabilidad debido a la falta de atención y el no reconocimiento de sus necesidades, lo que incide sobre diversas problemáticas, como la disminución de medios de subsistencia, la imposibilidad de contar con una vivienda digna, obstáculos y restricciones para acceder a sistemas de salud, educación y otros tipos de servicios para satisfacer sus necesidades básicas.

Es de resaltar que tanto en condiciones de desplazamiento como en situaciones donde familiares han padecido la desaparición forzada se observan múltiples implicaciones. Sin embargo, algunas son más silenciosas, como las relacionadas a la salud mental, así se expone en algunos estudios sobre desplazamiento (Campo y Herazo, 2014; Sánchez et al., 2019; Morina et al., 2018; Schlaudt et al., 2020; Vega, 2020) y en algunos estudios sobre desapariciones (Almanza et al., 2020; Gallardo y Saban, 2021; Lastra, 2019; Romero y Cuellar, 2021; Romero y Gómez, 2020). Dado lo anterior, surgen las siguientes preguntas: ¿qué sucede cuando en una familia se acumula más de un delito? - como es el caso de las familias que padecen la desaparición de uno o más integrantes y el desplazamiento forzado—, ¿cómo pueden resistir y sobreponerse?

Teniendo en cuenta las situaciones descritas, los procesos de resiliencia se muestran como alternativa para sobrellevar la adversidad y sobreponerse a ella (Cyrulnik, 2001). Al respecto, Puelles (2018) expone un enfoque desde una perspectiva de afrontamiento resiliente para quienes han padecido la desaparición de un familiar en España, donde puntualiza la importancia de apoyar a los familiares desde un principio en diversas acciones para potenciar su resiliencia. De forma similar, a través de un estudio realizado con familias desplazadas en Colombia, López (2005) develó que los procesos de resiliencia son posibles bajo circunstancias de extrema violencia y adversidad, pues surgen a través de recursos individuales, familiares y sociales, que son factores importantes para la resiliencia familiar.

Generar resiliencia no responde a determinismos lineales, por el contrario, responde a un proceso complejo (Salazar y Castro, 2021). En este sentido, es importante visualizar no solo factores personales, sino también factores que dependen de las interacciones con los otros, es decir, el apoyo dado al menos por otra persona es esencial para la reconstrucción resiliente (Torralba, 2013).

A este tenor, surgió otra pregunta: ¿¿cuáles son las redes de apoyo social con las que cuentan las personas desplazadas con familiares desaparecidos para sobrellevar la adversidad y sobreponerse a ella? Atendiendo a las anteriores preguntas, ha sido desarrollado el presente análisis, donde fue relevante profundizar si las familias afectadas por ambos delitos cuentan con redes de apoyo que les permitan reconstruirse frente a escenarios adversos tan complejos.

\section{Marco teórico}

El eje analítico de este estudio se construye a partir de dos principales referentes teóricos: la resiliencia y la red de apoyo social. De esta forma, es posible pre- 
sentar un análisis orientado a indagar sobre la relación entre las redes de apoyo social y la generación de procesos resilientes dentro de las familias.

La génesis del concepto de resiliencia surge de la ciencia física para hacer referencia a la elasticidad y capacidad de un cuerpo para recuperar su tamaño y forma original después de ser doblado, estirado o comprimido (Kotliarenco et al., 1997; Monroy y Palacios, 2011; Villalba, 2003). En lo concerniente al estudio de la resiliencia en los seres humanos, el concepto ha sido relacionado con los procesos de adaptación positiva de niños que viven condiciones de adversidad, desde una perspectiva psicológica y psiquiátrica (Klinkert, 2003; Masten, 2001). Es importante señalar que la resiliencia no es un proceso exclusivo de la niñez, ya que puede ocurrir tanto en una persona adulta como en un grupo o comunidad (Amar et al., 2003; González-Arratia y Valdez, 2013; Lavretsky, 2014).

De esta manera, el término resiliencia emerge como un concepto holístico, con el cual es posible profundizar en la investigación social orientada a explorar las capacidades personales e interpersonales y las fuerzas internas que se pueden desplegar para afrontar situaciones de adversidad (Villalba, 2003). En este estudio se reconoce el concepto de resiliencia como un proceso que requiere del equilibrio dinámico de diversos factores internos y externos que faciliten un desarrollo para sobrellevar la adversidad y episodios traumáticos y sobreponerse a ellos de tal forma que se pueda lograr una transformación y realizar un proyecto de vida (Cyrulnik, 2001; Salazar y Castro, 2020; Scoloveno, 2017; Villalba, 2003).

Al visualizar la resiliencia como un proceso, es posible analizarla desde dos enfoques: "mínimos», que aluden al rol de la adaptación, y «máximos», que se refieren a la transformación y al crecimiento (Gómez y Kotliarenco, 2010). Es importante tener en cuenta tanto elementos relacionados con la persona, el contexto y las circunstancias como los niveles de resiliencia de cada individuo. Para Evans y Reid (2016), la resiliencia es más que una llamada a incrementar una vigilancia ante ataques inminentes y la preparación contra ellos, también alienta a los actores a aprender de las experiencias y promueve acciones para sobreponerse de tal modo que la vida pueda continuar. Se reconoce que los procesos resilientes que ocurren después de haber sufrido un evento violento se construyen a partir de un elemento clave: dar sentido a la experiencia negativa a través de la comprensión del suceso e integrarlo a la propia vida, es decir, se requiere una interpretación que permita desarrollar pensamientos y acciones que faciliten emerger del estado de trauma (Cyrulnik, 2001).

La resiliencia se teje en forma relacional y narrativa. A través de un razonamiento narrativo, se descubren las posibilidades de la autorrestauración y el crecimiento en la adversidad (Cyrulnik, 2001). Los lazos relacionales fomentan razonamientos de colaboración, eficacia y confianza que facilitan afrontar las dificultades (Salazar y Castro, 2021), lo que permite una unión de personas y sistemas que ayuda a transitar hacia una trayectoria compartida (Gómez y Kotliarenco, 2010).

Para Granada (2018), la resiliencia que se genera de forma comunitaria tiene una estrecha relación con la inteligencia colectiva. Esta última es enten- 
dida como la capacidad generativa para producir nuevas prácticas sociales y entornos de protección que minimizan el caos frente a la adversidad y ofrecen espacios de confianza. Acorde con esta autora, la resiliencia comunitaria hace uso del conocimiento en el contexto apropiado a través del engranaje de saberes para la resolución de problemas y el cuidado de la vida. En este sentido, se enfatiza que las acciones de solidaridad en situaciones de necesidad generan mayores capacidades grupales para procesos resilientes.

El apoyo social se entiende como un conjunto de recursos humanos y materiales con los que cuenta una familia o un individuo para afrontar una crisis (Gallar, 2006), constituye la ayuda emocional o instrumental que, para una persona, se deriva de un determinado entramado de su red social (Sluzky, 1998). Para Thots (1985), el apoyo social hace referencia al grado en que las necesidades sociales de un individuo son satisfechas a través de la interacción con otros. También alude a la disponibilidad de personas o instituciones que ofrecen ayuda y demuestran interés por gente que vive situaciones en las que requiere soporte (Ferreira et al., 2012).

La red social es entendida como un conjunto de relaciones percibidas como más significativas por las personas, que contribuye al propio reconocimiento del individuo (Clemente, 2003). El análisis de la red social puede desarrollarse a través de su estructura — que está relacionada con el tamaño, la distribución, la dispersión, la homogeneidad o la heterogeneidad, atributos de vínculos específicos y tipo de funciones-, de sus funciones - que se aprecian en el intercambio interpersonal suscitado con la compañía social, el apoyo emocional, la guía cognitiva y el consejo, la regulación o control social, la ayuda material y de servicios, el acceso a nuevos contactos - y de los vínculos - que pueden ser analizados a través de las funciones, la multidimensionalidad, la reciprocidad, la intensidad o el compromiso de la relación, la frecuencia de los contactos y la historia de la relación (Clemente, 2003).

En concordancia con Sluzky (1998), el constructo de redes de apoyo social se conforma a través de componentes estructurales — se refiere al entramado de relaciones sociales—; del apoyo social percibido y recibido —el apoyo percibido se refiere a la dimensión subjetiva con la que el individuo valora las fuentes de apoyo en función de la satisfacción y adecuación de sus necesidades—; de la multiplicidad de funciones del apoyo social — se refiere a las consecuencias positivas que tienen las relaciones sociales para el sujeto—; de las conductas de apoyo —-se refiere a los comportamientos específicos de interacción social que tienen incidencia positiva sobre los otros-, y del contexto en el que se proporciona el apoyo -donde las conductas de apoyo responden al contexto en el que se desarrollan.

\section{Método}

El camino metodológico del presente estudio se desarrolló bajo el paradigma cualitativo y desde un enfoque fenomenológico. La selección de participantes se realizó tras un proceso de rapport que permitió un acercamiento durante dos años con diferentes colectivos conformados por familiares de personas desapa- 
Cuadro 1. Datos de participantes

\begin{tabular}{lcclcc}
\hline Participante & Edad & $\begin{array}{c}\text { Número } \\
\text { de integrantes } \\
\text { en la familia }\end{array}$ & $\begin{array}{l}\text { Familiar } \\
\text { desaparecido }\end{array}$ & $\begin{array}{c}\text { Edad del familiar } \\
\text { desaparecido }\end{array}$ & $\begin{array}{c}\text { Año de la } \\
\text { desaparición }\end{array}$ \\
\hline Ana & 33 & 3 & Hermana & 21 & 2017 \\
Álvaro & 55 & 4 & Hijo & 30 & 2018 \\
Adrián & 28 & 3 & Padre & 52 & 2017 \\
Brisa & 22 & 3 & Padre & 25 & 2020 \\
Catalina & 53 & 2 & 1 hija y 1 hijo & 37 y 35 & 2010 \\
Cesar & 48 & 5 & 2 hermanos & 40 y 42 & 2009 \\
Lola & 37 & 3 & Esposo & 39 & 2017 \\
Matías & 45 & 3 & Hermano & 47 & 2012 \\
Román & 67 & 4 & Hijo & 33 & 2017 \\
Sara & 55 & 8 & Hija & 26 & 2012 \\
\hline
\end{tabular}

Fuente: elaboración propia con la información provista por los participantes en el estudio y bajo la asignación de un seudónimo.

recidas. De esta forma, fue posible contactar con familias que habían sufrido el desplazamiento forzado interno en los estados de Guerrero y Veracruz hacia ciudades ubicadas en el centro del país, y que buscan a sus familiares desaparecidos en las regiones donde ocurrió el desplazamiento.

La técnica de recolección de información fue principalmente a través de entrevistas en profundidad. También se desarrolló observación participante durante diferentes acciones y procesos de búsqueda que los colectivos organizaron entre febrero de 2019 y febrero de 2020. Las entrevistas duraron entre 90 y 120 minutos y, bajo la anuencia de los participantes, fueron audiograbadas, transcritas y analizadas con el software MAXQDA versión 12.

En total se contó con 10 participantes, y la identificación de quienes integraban sus familias fue proporcionada por ellos mismos. Los principales datos son sistematizados a continuación:

El cuidado sobre los aspectos éticos de este estudio fue fundamental. El desplazamiento forzado de los participantes ocurrió bajo dos principales dimensiones: la amenaza directa y la salvaguarda de las familias. Ambas fueron suscitadas después de haber sufrido la desaparición de uno o más familiares, entre otras expresiones de violencia. Por ello, explicarles con detalle la intencionalidad del estudio, garantizar su participación cuidando el anonimato, contar con el consentimiento informado y orientar la indagación en función de su cuidado emocional para evitar el desbordamiento fueron pilares en esta investigación.

\section{Resultados}

Los resultados han sido organizados conforme a los ejes de análisis que se estructuraron en relación con las narrativas de los participantes. A este tenor, es importante exponer la siguiente disposición: los contextos y las redes de apoyo 
social que dan soporte cuando ocurre el desplazamiento; los apoyos percibidos ante la imposibilidad de vivir un duelo por la pérdida ambigua; la relevancia de las redes de apoyo social para los procesos de resiliencia, y los retos y estrategias de apoyo social al volver a los territorios donde ocurrió el exilio para realizar la búsqueda de sus desaparecidos.

\subsection{Las familias vulneradas y los apoyos en medio del desastre}

Las experiencias padecidas por las familias exponen el alto grado de vulnerabilidad frente a la violencia vinculada con grupos del crimen organizado en sus regiones. En algunos hogares se suscitaron diferentes delitos, entre los que la desaparición es el considerado más grave. En siete familias el desplazamiento ocurrió meses después de la desaparición, en un caso ocurrió un año después y en otro siete años más tarde. De los primeros siete casos, cuatro familias exponen que fueron amenazadas directamente por los grupos criminales que hicieron desaparecer a sus familiares y esto generó rápidamente su desplazamiento; en los tres casos restantes, los participantes exponen que las desapariciones fueron propiciadas por policías municipales coludidos con los grupos criminales, lo cual derivó en sentimientos de inseguridad, y el desplazamiento resultó ser una decisión para proteger al resto de la familia.

Los otros tres casos restantes se suscitaron debido a las siguientes situaciones de riesgo. Un año después de que el hijo de Alberto desapareciera, en un evento público, él exigió al presidente municipal de su entidad que atendiera el caso de su chico desaparecido, el cual estaba relacionado con su detención por parte de policías municipales. A partir de ese momento, se generaron diversos actos de represión y el último de ellos fue un atentado contra su hijo menor. El caso de Matías no fue muy diferente, pues también responde a un atentado directo contra su persona a raíz de desenterrar un cuerpo en una fosa clandestina - «desenterré el cuerpo equivocado». Se presume que el cuerpo hallado correspondía a una persona que tenía poco de haber sido reportada como desaparecida, y esto generó amenazas directas del grupo delictivo. Matías había dedicado años a las búsquedas en terreno y a las búsquedas en vida desde su región de origen, con el objeto de encontrar a su hermano, que fue secuestrado y posteriormente desapareció en ese estado. Pese a que sus continuas búsquedas y denuncias ya habían causado evidente molestia entre los miembros de los grupos delictivos y algunas autoridades, no fue hasta esa agresión que se produjo el desplazamiento forzado. En el caso de Lola, meses después de la desaparición de su esposo, al no tener respuestas positivas de las autoridades, organizó diversas brigadas de búsqueda en áreas donde sospechaba que podía haber fosas clandestinas, un trabajo que se intensificó con los años. En varias ocasiones fue amenazada por miembros de un grupo delictivo, pero no fue hasta al cabo de tres años, cuando su casa fue incendiada, que se materializó el desplazamiento de ella y su familia.

Para las familias, los sentimientos de impotencia y enojo son una constante durante los primeros meses. Además, manifiestan una profunda percepción 
de pérdida de control, donde todos los integrantes están expuestos. También señalan que la primera fuente de apoyo fue vital, otorgada por quienes, pese al miedo, les recibieron en su hogar y les proporcionaron algunas noches de asilo. Junto con lo anterior, las familias comparten que las condiciones de violencia en las que tiene lugar el desplazamiento les impiden disponer de sus propiedades, de modo que sus hogares quedan amueblados a la deriva de quienes se ofrezcan a cuidarlos o, incluso, en pleno abandono.

El primer paso de las familias ante el ineludible desplazamiento fue recurrir a parientes que vivían en otras ciudades, pero solo dos de ellas obtuvieron una respuesta positiva de sus familiares. En otros dos casos, manifiestan que la respuesta de apoyo vino de amigos cercanos que vivían en otros estados, y en el resto de los casos el asilo fue proporcionado por familias que buscan a sus desaparecidos, con los que ya tenían un acercamiento previo, a excepción de una familia que fue remitida con otra familia que había sufrido un desplazamiento previo (a raíz también de la desaparición de uno de sus integrantes) a través de una organización no gubernamental de derechos humanos.

Román y su esposa quedaron a cargo de sus dos nietos a raíz de la desaparición de su hijo; Ana fue desplazada, junto con su madre y dos hijas, al enfrentarse a una red de trata de personas por la desaparición de su hermana, y Lola sufrió el desplazamiento junto con sus dos hijos pequeños.

Huir con niños es difícil, muy difícil. Nosotros somos gente mayor, pero somos todo lo que tienen. Mi hijo tenía amistades, y él, él, estuvo en el lugar y momento equivocados. Al otro joven lo mataron, encontraron a los dos días su cuerpo. El de mi hijo no, él sigue desaparecido. Se soltó mucho miedo, fue difícil obtener ayuda. A nosotros nos amenazaron. ¿Qué podíamos hacer? Mi cuñada y su familia nos recibieron, se nos acomodó en una recámara a todos. Mi esposa no dejaba de llorar, fueron momentos muy duros. Dejas todo, dejas todo aquello en lo que se te fue la vida, pero nada de eso importa, cuando lo más doloroso es traer un cachito del alma perdido. (Román)

La ayuda no vino de la familia, todos tenían miedo, y los pocos que vivían fuera no, no nos contestaron ni las llamadas. Pedí ayuda a una señora que es líder de un colectivo de familiares, obvio, de otra ciudad. Ella busca a su hijo y yo le pedí que nos ayudara. No lo pensó, te lo juro, me dijo: «Vengan, pero vengan rápido y no le digas a nadie a donde van». (Ana)

Nadie, nadie de la gente cercana me ayudó. Las mismas del grupo me dijeron: «Vete y córrele, porque nos pusiste en riesgo a todas». No sé, quizás tenían razón, pero yo tenía mucha rabia, pero una aprende, una aprende. A nosotros nos recibió otra familia que ni conocíamos, ellos también habían sido desplazados, también cargaban con su desaparecido. A ellos los contactó la asociación, y me ayudaron, pero es que ellos sí tenían medios económicos, al menos más que yo, sí tenían. (Lola)

Durante los primeros meses, a pesar de que las familias se encontraban lejos de los lugares donde sufrieron el daño, existía un permanente estado de alerta 
que daba paso a percepciones de vulnerabilidad y no les permitía tener tranquilidad. Entre las narrativas, sobresalen experiencias similares sobre dificultades para dormir, sentirse perseguidos, despertar sobresaltados, tener pesadillas recurrentes, problemas para entablar nuevas relaciones sociales, desarrollar sentimientos de desconfianza, padecer ansiedad y el desarrollo de taquicardias. Reconocían que requerían apoyo terapéutico, pero que en los primeros meses no podían ocuparse de esta necesidad, la forma de contenerla era a través de compartir lo que sentían con personas que también tenían familiares desaparecidos. Así lo expresa Sara.

Nadie nos va a entender. Solo nosotros, que padecemos lo mismo, solo nosotros, que padecemos el dolor, somos los que sabemos qué sentimos, solo nosotros nos vamos a entender, porque la gente que no lo ha vivido, no se hace sensible con nosotros, y la gente que sí lo ha vivido se sensibiliza con nuestro dolor. Entonces entre nosotros nos buscamos para hablar, para sostenernos. (Sara)

Los participantes comparten que durante los primeros días se ocupan de evaluar sus recursos humanos y materiales para afrontar su nueva condición y planear estrategias en conjunto. Las familias que contaban con dinero ahorrado pudieron pagar hospedajes o rentas de espacios provisionales durante las primeras semanas.

De entrada, llegamos con otra familia que también busca a sus desaparecidos, el miedo es cabrón, no confías en nadie más que en los que andamos en lo mismo, ya ellos nos apoyaron y orientaron, acá sí, acá no. Revisamos cuánto dinero teníamos, y pues rentamos una casita pequeña. Ahí empezamos a organizarnos, mis chamacas se portaron fuertes y aguantaron todos los cambios e incomodidades, mi papá, aun con su incapacidad, tampoco se quejó. Si no hubiéramos tenido un guardado, no sé, no sé qué hubiéramos hecho. (Cesar)

En otros casos, las condiciones económicas no les permitieron organizarse de manera independiente durante los primeros meses, por lo cual adaptaron sus dinámicas familiares en función de las dinámicas establecidas por la familia de acogimiento.

Tú te tienes que adaptar, ahí no hay forma de negociar. Mi mamá a hacer la limpieza como la señora lo hacía, mi hermanito a levantarse temprano aun los fines de semana, ja, ja, ja, pobre, yo a vestirme más tapada y a no decir groserías, uta, no sabes lo que me costó, ja, ja, ja, hasta a misa hubo que ir, pero el dinero manda y en casa ajena, pues... (Brisa)

\section{2. ¿Y al guardar las maletas? La pérdida ambigua y el duelo imposible}

Una vez que las familias habían resuelto sus necesidades más apremiantes, como son la vivienda, la comida y las fuentes de ingresos (aun cuando fuese de manera intermitente), comenzaba otra etapa que sacaba a flote sentimientos 
que habían procurado mantener en un estado de latencia, en algunos casos para no «incomodar» a las familias que les habían ofrecido asilo y en otros para no generar más angustia en la familia inmediata. Para las familias participantes, el desplazamiento en sí es la menor de sus angustias y preocupaciones. Si bien representa un detonante importante que incide sobre sus formas de vida y organización familiar, la situación que más les ocupa psíquicamente es la desaparición de su familiar o familiares. Entre los sentimientos más recurrentes, se encuentra el enojo y la impotencia. Asimismo, los participantes expresan que los sentimientos de culpa son constantes y, en algunos casos, conllevan periodos de depresión y profunda tristeza.

Quería gritar, llorar, quería romper cosas, pero no estaba en mi casa. Me preguntaban: «¿Estás bien?». ¿Quién chingados va a estar bien cuando te desparecen dos hijos? Estaba que me quería morir, pero no les contestaba, les sonreía y trataba de estar calmada. Mi hijo era el único que sabía lo que sentía, él se sentía igual, los dos teníamos mucha culpa, pero de eso yo me enteré después. Se sentía tan culpable como yo, pero de primero no lo dijimos, las cosas, de por sí, ya estaban tan jodidas. Pero cuando estuvimos aparte, se soltaba la chilladera, el griterío, una vez rompimos botellas juntos, contra la pared, no rompíamos más cosas porque, porque no teníamos más que un colchón y la parrillita. (Catalina)

A mí me vale, madre, estar desplazado, mi vida no se acabó por esto, mi vida se consume porque a mi papá se lo llevaron por mi culpa, eso nada lo va a cambiar. Aunque me digan y me digan que eso no es cierto, cuántas veces, cuántas veces he deseado estar en su lugar. Si no fuera porque se lo tengo que regresar a mi mamá y a mi hermana, yo ya no estaría aquí, mis tíos lo saben, ellos saben, saben que estoy aguantando por ellas, trato de no llorar, pero me duele mi padre, me duele un chingo. (Adrián)

Para las familias que tienen integrantes desaparecidos, la incertidumbre que genera la pérdida ambigua es la principal causa del deterioro de su salud. De acuerdo con sus experiencias, esta puede causar en algunos casos la muerte.

Yo la veo a ella, siempre fue fuerte, pero desaparecen a mijo y es cuando se me vino abajo, que la presión, que el azúcar, todo le paso a mi señora, pero yo la entiendo, porque, aunque no lo diga, yo también me siento enfermo. ¿Cómo no enfermar? Si todo, todo el día estás pensando si vive o muere, si come, si tiene frío, si lo obligan a hacer cosas, todo el día, las 24 horas piensas en tu hijo desaparecido. Piensas más en ellos cuando no están que cuando están. Cuando te los arrebatan así, parece que nomás se llevan el cuerpo, porque los traes en la mente, los ves en todos lados, los traes en el corazón, los sientes en todas partes, los llevas a donde vas, los sueñas, en cada respiro te hacen falta. Hay quienes mueren por eso, a veces siento que poco nos falta. (Román)

Mi madre, ella se nos fue a raíz de lo de mi hermana. Primero se enfermó de azúcar, luego la presión, y es que acá la altitud me la tiraba. Extrañaba su tierra, como le lloraba a sus árboles, sus plantas, su casa. $\mathrm{Al}$ año le vino el cáncer, se 
me fue rápido, y yo sé que fue por eso ¿Por qué más? Todo el día pensaba en ella, se preguntaba que cómo estaría, que si vivía, que si le pegaban, todo se preguntaba, no había más mundo que ella. Cuando hacía de comer, hacía para ella, nosotras nada más la mirábamos, no le decíamos nada. (Ana)

Asimismo, manifiestan que la ayuda terapéutica que ofrecen las instituciones gubernamentales, lejos de ser un apoyo, incide sobre sus sentimientos de impotencia y desesperanza respecto a la forma de actuar gubernamental.

Me mandan a mi mamá al psiquiátrico, y el psiquiatra que le dice: «Ya supérelo, viva el duelo, entiérrelo, hágalo por sus hijos». Están pendejos, por eso dejamos de acercarnos a pedir ayuda, a huevo quieren que cerremos el duelo, ¿qué duelo?, ¿qué chingado duelo? Si mi papá está vivo, vivo hasta que se demuestre lo contrario, lo que pasa es que les urge que dejemos el tema por la paz, porque ya no pueden, somos tantos, que ya no pueden, así que ayuda, en nada ayudan, el gobierno no ayuda, solo quieren que los dejes de chingar. (Brisa)

A través de los casos participantes, no solo la desaparición de sus familiares les genera sentimientos de pérdida ambigua, sino también el hecho de no poder tener espacios dentro de sus nuevos hogares que permitan hacer referencia a quienes han desaparecido.

Me dice mi compañera: «¿A poco tú no tienes todo tal como lo dejó tu hija? Yo hasta su ropita sucia la tengo guardada». No, no tengo nada, bueno tengo a su hija, mi nieta, a ella la tengo. Qué más quisiera yo haber podido guardar sus cosas, quedarme en la casa para sentirla, para recordarla, decir ahí se escondía, ahí fue donde aprendió a caminar, pero nada de eso tengo, en donde vivimos no hay historia, hay lágrimas, eso sí hay. (Sara)

El hecho de pasar demasiado tiempo en los nuevos espacios de asentamiento incide sobre el estado de depresión y ansiedad, por lo cual procuran buscar ocupaciones fuera del hogar. Los participantes expresan que, si bien los sentimientos de dolor son experimentados en diferentes momentos del día, la angustia se intensifica por la noche. La reducción de actividades físicas da a lugar a diferentes pensamientos relacionados con la persona desaparecida, los recuerdos aparecen y los referentes a su desaparición ocupan gran parte del pensamiento, lo que genera ansiedad y malestar. En palabras de Catalina:

Me salgo, no puedo, no puedo quedarme en la casa, me deprimo, me muero de tristeza, mi hijo tampoco se queda, me dice: «Me quedo y me duele feo acá dentro, madre». Yo lo entiendo, nos duele casi igual. Yo me salgo a vender y a buscar, voy vendiendo, voy buscando, pregunte y pregunte, Dios sabe. Pero llega la noche, ¡ay, Dios mío! Una acostada está, piense y piense, que ¿por qué se llevaron a mi hijo? Que se llevaron a mi hija por mi culpa, que para qué le avisaba, que para qué regresaba, no, no, no, quieres cambiar la historia y no puedes, no puedes.

Los participantes señalan que la desaparición de un ser querido también implica la pérdida de un "pedazo» de sí mismo, lo cual les genera una heri- 
da imposible de cerrar. Además, argumentan que esta percepción también es visible en otros integrantes de sus familias, y que finalmente lacera a la familia entera. Así lo comparte Adrián:

Tú miras a mi hermana y no es la misma, desde que pasó lo de mi papá dejó de ser bromista. En la familia siempre andábamos de pesados, nos hacíamos cada cosa, pero ¿̇ahora? Ahora me habla poco, y mi mamá, a suuu, mi mamá, ella dejó de ser madre, pasó a ser nuestra hija.

Algunos participantes manifiestan que la cohesión y la comunicación que se pueda dar en la familia contrarresta y disminuye estos malestares, les permite organizarse para la resolución de sus problemas más apremiantes, y se reconoce la necesidad de encontrar a quien se encuentra desaparecido. De esta forma, se distribuyen tareas y responsabilidades.

Mi hijo es el que trabaja más temporadas, porque en las brigadas tiene que renunciar, él es el que escarba, pico y pala, pico y pala, yo camino y ando, pero escarbar no puedo, así que yo ando en las búsquedas en vida, en las fiscalías y todo. Mi nuera cuida a los niños, a veces también se viene y todos andamos en bola buscando. Porque en la familia somos bien claros, los niños saben que andamos buscando a mi hija, hay mucha comunicación y por eso hay unión. Todos juntos. (Sara)

Estamos muy unidos, lo que nos pasó nos unió más, eso y contarnos lo que nos pasa nos ayuda a consolarnos, a darnos fuerza, a no caernos. Solo con comunicación nos hemos podido organizar. Yo, que soy maestro, eso les he enseñado, y nos hemos organizado. Mi hija se puso a trabajar, mi esposa anda vendiendo comida, ahorita no hay de otra, mi hijo y yo andamos aquí, buscando y buscando, rascando, preguntando, pegando los carteles, no paramos. (Álvaro)

Como es posible observar, las familias se enfrentan a diversos retos, entre los que el desplazamiento ocupa la menor de sus preocupaciones, pues la desaparición de sus seres queridos es la situación más grave a la que deben hacer frente y ponderar su búsqueda.

\subsection{Reconstruirse a través de las redes de apoyo. El abrazo resiliente del apoyo otorgado y del apoyo percibido}

Para las familias, sobreponerse es una necesidad que se menciona reiteradamente y que está orientada a no "perder» más integrantes de la familia y a enfocarse a que la persona desaparecida regrese a casa. Sin embargo, generar acciones que permitan sobrellevar las diferentes adversidades ocasionadas por los eventos violentos y lograr reconstruirse de manera personal, familiar y social parte de un proceso que no está libre de complejidades. El proceso resiliente no responde a capacidades individuales, sino que más bien se desarrolla con los vínculos que les permiten dar significado a sus nuevas realidades. Los 
participantes exponen que la primera red de apoyo se encontraba dentro de la familia desplazada:

...mis chamacas, luego me veían batallar con el dinero, y ahí andaban ayudándome a vender, sonriendo. Verlas tan chiquitas y ya luchando. ¡Te levantas porque te levantas! (Ana)

Fue sabernos juntos, saber que cada quien haría algo para que no nos llevara la chingada; yo me caía, mi esposa me levantaba, mi papá se venía para abajo, yo salía al quite, así, entre todos. No ha sido fácil, pero nadie se aferra a estar en el suelo. (Cesar)

Además, las familias se organizan para consensuar quienes participarán en las brigadas de búsqueda. Estas decisiones son tomadas sobre la base de mantener la generación económica que les da sustento y cuidar de los que se encuentran más vulnerables. No obstante, no en todas las familias se puede evitar la no exposición de los integrantes más vulnerables. También existen dificultades para lograr consensos sobre quienes son proveedores para que se mantengan al margen de las búsquedas, cuando estos consideran que la necesidad de buscar es primordial y que la generación de ingresos puede esperar. Los siguientes argumentos ejemplifican lo dicho.

¡La segunda red de apoyo se encontraba en quienes les habían acogido en sus hogares. La forma de retribuir era no dejarse caer y fortalecerse para cuando se requiriera su ayuda. En este sentido, algunas de las familias de este estudio se han organizado incluso para acoger a otras familias desplazadas con integrantes desaparecidos.

Mi casa es pobre, tú lo puedes ver, pero hay donde cocinar, hay donde dormir, hay donde bañarse, aquí cabemos todos, aquí ya van tres familias que llegan conmigo, una se quedó seis meses. Aquí nos las arreglamos, venían con niños como yo, que les digo que el tiempo que necesiten, pero, eso sí, aquí vienen para no dejarse caer, llorando, pero buscando, les digo. (Lola)

...si una familia se tiene que salir hay que apoyarla, en la casa cabemos todos, ya luego van buscando su propio lugar, pero primero sí, hay que apoyar, yo apoyo a mi gente de esa manera, porque tenemos que seguir buscando. (Sara)

Para las familias, construir redes de apoyo social con familias que también buscan a sus seres queridos desaparecidos - a las que identifican como «familias hermanas del mismo dolor»— les permite generar acciones de solidaridad que inciden sobre sus propios procesos de resiliencia y fortalecimiento.

Cada quien ayuda como puede, yo doy mi cuerpo, tuve que prepararme físicamente, aprender a rapelear, aprender a escalar, hasta aprender a nadar. $\mathrm{Ni}$ modo que las madres se metan a los pozos, anden rapeleando, pues no, míralas, son fuertes, pero yo tengo más años, bueno, creo. Yo a donde me llamen voy, siempre buscando a Daniel, siempre buscándolo, pero busco también a 
todos, porque ellas buscan de otras maneras en otros lados, así somos familia, ayudándonos, resistiendo, creciendo. (Matías)

En las brigadas conocí a Anahí, ella también busca a su papá. Tú a veces no puedes encajar con todos, pero ella y yo nos hicimos como hermanos, pero yo soy el menor, ja, ja, ja, y andamos ayudando. Ella es bien movida, a veces yo nomás la sigo, me dice: «Ándale, chamaco, mueve las manos que hay que recoger a estas mujeres para volverlas a pegar». Eso es lo que me levanta. (Adrián)

Asimismo, señalan que pertenecer a grupos y colectivos les permite tener espacios catárticos, de aprendizaje, espirituales y de hermandad. De esta forma, ser parte de colectivos o grupos de familiares que buscan a sus desaparecidos les permite reestructurar su identidad y les genera percepciones de fortaleza. Además, realizar acciones de búsqueda y demanda de justicia incide sobre una autopercepción de empoderamiento, donde la adversidad no determina quienes son, sino que son ellos y ellas quienes determinan cómo viven esa adversidad.

\section{4,4. Regresar, buscar, afrontar y despedirse de nuevo}

Dentro de las diversas situaciones complejas que estas familias afrontan, se encuentran las relacionadas con los procesos de búsqueda en las regiones donde sufrieron la desaparición o el desplazamiento. Al ser las familias de este estudio desplazadas de los estados de Guerrero y Veracruz, el eje de análisis desarrollado de realizó a partir de las vivencias que los participantes experimentan durante los procesos de búsqueda en terreno y búsqueda en vida en estos estados. Existen tres temporalidades que exponen la permanencia de su vulnerabilidad y sus recursos para afrontarlos de forma resiliente: el impacto del regreso; afrontar la permanencia de la vulnerabilidad y violencia; despedirse de los lugares que «dan y quitan vida». En estos procesos, las redes de apoyo social cobran relevancia no solo porque les fortalecen de manera emocional, sino también porque inciden sobre su salvaguarda y protección. Respecto a la primera temporalidad y la vulnerabilidad percibida, comparten:

Regresé, sí, sí tenía miedo, pero me sentía protegido porque éramos un chingo de familiares, toda la brigada, pero me caí, me caí porque se me vinieron los recuerdos. (Matías)

No se lo deseo a nadie, a nadie, llegar y ver lo que fue tu casa, volver a sentir como se llevan a tu hija enfrente de ti, acariciar el suelo, gritar que te los regresen. (Catalina)

Mucha impotencia, mucha, mucha impotencia. "Yo no me quiero vengar, venimos a buscar», les gritaba llorando cuando recién llegamos. (Álvaro)

Regresar a las brigadas de búsqueda en los territorios donde sufrieron el exilio implicaba diferentes retos donde tenían que realizar evaluaciones sobre 
su salvaguarda. En los estados de Guerrero y Veracruz, la violencia continúa siendo parte de la cotidianidad, las ejecuciones, las desapariciones y los secuestros son delitos recurrentes que se siguen perpetuando. Asimismo, las familias afirman que los grupos que perpetran estos actos siguen delinquiendo. En Guerrero, miembros de un grupo delictivo hicieron llegar mensajes a integrantes de una brigada de búsqueda ${ }^{3}$ en los que amenazaban que existían zonas donde, «por su propia seguridad», no deberían buscar. Durante una brigada de búsqueda en Veracruz, en un poblado determinado, ${ }^{4}$ se había obtenido apoyo e información de algunos ciudadanos sobre lugares de «exterminio» donde se podían encontrar restos humanos. Después estas personas fueron coartadas y amenazadas. La forma de afrontar estos hechos y reducir la vulnerabilidad responde a las estrategias desarrolladas de forma colectiva y a solicitar apoyo a instituciones de seguridad, de preferencia que no pertenezcan a la región, con la inclusión de observadores internacionales en materia de derechos humanos.

Me dijeron: «Dejen de estar chingando, dejen de estar buscando, no nos calienten la plaza». Hay lugares donde no se puede buscar, no tiene caso buscar muertos enterrando vivos. Entonces teníamos que ser estratégicos, y enfocar esfuerzos a donde sí pudiéramos tener resultados. Además, quieras o no, que nos resguarden con seguridad es un apoyo. (Matías)

Cuando una anda buscando a su sangre, se hace fuerte porque se hace, dejas al lado el miedo, en grupo te sientes empoderada. Yo que enfrento a las autoridades y que les digo: «¿No saben buscar? Nosotras les enseñamos cómo. ¿No pueden solos? Acompáńenos, entonces, necesitamos resguardo mañana en la búsqueda, ¿¿cuántas patrullas nos van a mandar?». Y así fue como ejercimos presión, pero íbamos acompañadas por un observador internacional, eso ayudó. (Brisa)

Además de lo anterior, las familias están convencidas de que dentro de las brigadas de búsqueda es primordial realizar evaluaciones de los entornos sociales y ponderar las fortalezas grupales para enfrentar los diferentes retos. También es relevante llevar a cabo acciones orientadas a sensibilizar a los habitantes de las zonas donde trabajan las brigadas. Desde su perspectiva, se logra minimizar su exposición al riesgo al obtener apoyo social, se facilitan tanto acciones solidarias como de búsqueda, y con ello se obtienen más avances.

Gracias al apoyo de la gente, aunque sea anónimo, ¿de qué otra forma puede ser?, sabemos dónde buscar, de quienes cuidarnos. ¡Hace falta más!, pero es lo que pueden dar. (Cesar)

Tú también la viste, la viejita que llegó con su costal de pan, todos pensamos que venía porque buscaba a alguien, me conmovió, me conmovió cuando dijo: «Les traje pan, no se rindan». Y se fue, toda chiquita, a paso lento. (Álvaro)

3. Se omite información detallada por cuestiones de seguridad.

4. Se omite información detallada por cuestiones de seguridad. 
Todas aquí andamos enfermas, eso no es nuevo, pues que llega el médico del pueblo con una enfermera, y que nos forma, nos tomaron la presión, el azúcar ¡y túmbale!: «Tú vas, tú te quedas, tú necesitas medicamento». Y el berrinche, pero también el agradecimiento de que vean por nosotras. (Catalina)

En el momento en que terminan las brigadas de búsqueda y emprenden su regreso, existen decaídas emocionales relacionadas con la percepción de no tener éxito en la búsqueda de sus familiares. Este posicionamiento psíquico solo es aminorado cuando entre ellos desarrollan un abrazo social que les permite reconocer que el trabajo realizado puede dar paz a otras familias, al encontrar cuerpos o restos que permitan identificar a otras personas desaparecidas.

Me rompe, me rompe regresar y decirle a mi mujer que no los encontré, además te despides de todos, y sientes que, otra vez, te vas quedando solo, pero no falta quien te levante. Me dicen: «¡Órale, papá!, ¡échale ganas!». Me dejan riendo, mi mujer me dice: «No los encontraste, pero ya llevaste paz a una madre, a una esposa, no seas duro». (Cesar)

¿Qué más puedo hacer? Nosotras repetimos: «De buscar a nuestros hijos, pasamos a buscar a todos los desaparecidos y, de buscar a los desaparecidos, pasamos a hacer acciones para que no siga pasando». Nosotras encontramos, al encontrar y saber que alguien va a regresar a casa, pues es, es un abrazo, un apapacho al corazón, es la mejor forma de despedirse de los lugares de horror, dar paz. (Catalina)

Es importante resaltar que, dentro de sus experiencias durante las brigadas de búsqueda llevadas a cabo en sus regiones, siempre se han tenido hallazgos positivos, pero ninguno ha correspondido al integrante desaparecido de las familias en cuestión. Una realidad que lacera e incide sobre su cotidianidad y refleja la gravedad del desastre que la violencia y la impunidad han generado sobre las poblaciones. Las secuelas de la desaparición y las violencias que la generan son una cuestión pendiente de atender tanto gubernamental como socialmente. Hasta ahora, los procesos de reconstrucción de las familias que han sido víctimas han ocurrido gracias a su misma organización como redes de apoyo, y a la resiliencia que generan a través de los actos solidarios, los trabajos de búsqueda y el soporte continuo que se produce entre ellas.

\section{Discusión}

Las familias participantes han sido vulneradas, pero, además, la desaparición de uno o más de sus integrantes, el desplazamiento forzado y sus implicaciones también han incidido sobre su bienestar, al verse obligadas a abandonar sus bienes materiales, al quebrantarse sus redes sociales y depender de apoyos externos para una salvaguarda inmediata. En esta dirección, coinciden los estudios de Campo y Herazo, 2014; Marinis, 2017; Sánchez et al., 2019; Rubio, 2014; Velázquez, 2017 y Vega 2020 cuando señalan que quienes padecen el 
desplazamiento tienen largos periodos de sufrimiento, debido a la violencia, la economía afectada, el desarraigo, las pérdidas, la falta de vivienda digna, la falta de protección institucional, la violación de sus derechos humanos, las dificultades de reinserción social, laboral y escolar, el desarrollo personal interrumpido, entre otros. No obstante, a través de las narrativas de los participantes, se observa que el desplazamiento no es el principal problema que perciben, por el contrario, su atención se centra en los desaparecidos y se minimizan las otras problemáticas, que quedan en un segundo término.

Desde las experiencias de los participantes, fue posible apreciar que los entornos sociales de las familias se quebrantan debido al miedo y que esto reduce sus posibilidades de obtener apoyo social. Al respecto, Ruiz (2006) y Concha (2002) habían expuesto con anterioridad, en sus estudios realizados en Colombia, que el miedo a la victimización provoca inhibición de la comunicación, la desvinculación de procesos organizativos, aislamiento social, desconfianza y desintegración comunitaria, es decir, afecta el tejido social y reduce el capital social. Rodríguez et al. (2002) explican que el conflicto armado desarrollado durante más de tres décadas en Guatemala incidió de manera negativa sobre el capital social. La comunicación era escasa y esto se relacionaba con los procesos de inseguridad y miedo. Además, a juicio de quienes participaron en el estudio, existe una predominancia de la individualidad sobre la solidaridad. De acuerdo con los estudios de Miranda (2000), en El Salvador, en los casos de desplazamiento forzado se genera un sentimiento de pérdida de protección y seguridad cuando los integrantes se quedan sin referentes afectivos cercanos que les ayuden a contener las experiencias vividas.

Sin embargo, cabe destacar que en el presente estudio existe la percepción de obtener más ayuda y comprensión de familias que buscan personas desaparecidas y que en algunos casos también han sido desplazadas. Se aprecia que las familias desplazadas depositan sus referentes afectivos en redes de apoyo social conformadas por familias que viven circunstancias similares. En este sentido, lejos de sentir una lejanía afectiva, encuentran contención y refuerzan sus sentimientos de identidad y cohesión social al compartir experiencias y caminos de búsqueda de personas y búsqueda de una justicia restaurativa. Al respecto, se encuentra una similitud con los estudios de Palacio y Madariaga (2006), donde las autoras señalan que la disgregación de redes sociales debido al desplazamiento se convierte, en ocasiones, en una motivación para generar nuevas redes sociales con personas en situaciones similares. De igual forma, existe coincidencia con los hallazgos de Sierra et al. (2019), quienes han expuesto que las redes de quienes han sido desplazados se fortalecen a través de esos vínculos que se construyen al experimentar experiencias vulnerables similares.

En concordancia con lo anterior, coincidimos con Venturoli (2009), quien desarrolló un estudio en Perú con víctimas de la guerra civil. Señala que la participación que las mujeres desarrollan a partir de las secuelas de esta violencia y el hecho de organizarse para encontrar justicia para sus familiares muertos o desaparecidos les han permitido la creación de capital social a través del apoyo moral mutuo y el intercambio de estrategias para la búsqueda de familiares. 
También existe afinidad con González (2004), que, a través de su investigación con familias desplazadas en Colombia, explica cómo las mujeres de las familias muestran perseverancia para la reconstrucción de proyectos de vida y son las principales generadoras de estrategias para la construcción de nuevas redes de apoyo. Además, en relación con el estudio de Hoyos y Nieto (2016), es posible observar semejanza con los procesos organizativos de mujeres del Oriente Antioqueño en Colombia, los cuales se fundamentan en la reconstrucción del tejido social a través de colaboraciones entre pares.

Gracias a este estudio, se ha observado que el sentimiento de incertidumbre en estas familias respecto a sus desaparecidos es percibido como el obstáculo más grande para lograr una reconstrucción frente a las violencias padecidas e incluso sobre el desplazamiento forzado. Las familias entrevistadas sufren una pérdida ambigua que les genera diversas emociones negativas e incluso enfermedades y malestares físicos. Coincidimos en que la experiencia de una desaparición conlleva asumir la existencia bajo un profundo dolor, donde los sentimientos de culpa y angustia son constantes, debido a que la incógnita sobre su ser querido es una cuestión tormentosa (Delgado, 2014). También ha sido posible apreciar que los resultados del presente trabajo tienen similitud con los hallazgos de Bezanilla y Miranda (2014) cuando exponen que, en aquellas familias colombianas donde ha ocurrido la desaparición forzada de uno o más integrantes, se ha advertido la presencia constante de incertidumbre que deriva en trauma, donde la familia queda "suspendida» en un momento, con la pregunta constante sobre el paradero de la persona ausente. De la misma forma, Almanza et al. (2021) destacan también que la pérdida ambigua vulnera la salud mental de quienes tienen familiares desaparecidos, debido a que se presenta una sintomatología depresiva marcada por el retorno continuo del sufrimiento que implica la ausencia del ser querido.

Las familias participantes explican que no han recibido tratamientos terapéuticos de forma adecuada y señalan ineficacia y falta de sensibilidad por parte de los profesionales que les han atendido, los cuales, según sus argumentos, no comprenden la pérdida ambigua, la imposibilidad de vivir y cerrar un duelo. Además, indican que les hablan constantemente de superación y que entre las alternativas de recuperación existe una constante recurrencia a medicamentos como ansiolíticos y antidepresivos, que, desde la perspectiva de los participantes, solo tienen un efecto paliativo y los inmoviliza. No obstante, lo considerado como más grave es que, en algunos casos, les piden referenciar a sus desaparecidos como si ya estuviesen muertos. Cabe mencionar que el auxilio terapéutico al que se hace referencia es el que las instituciones gubernamentales les han brindado, ya que para las familias el pago de terapias no es un gasto que se encuentre entre sus prioridades debido a dos situaciones principales: el desplazamiento y los procesos de búsqueda, a los que prefieren destinar sus recursos.

Acorde con lo anterior, es preciso que las instituciones que otorgan asistencia a estas familias consideren integrar otras perspectivas en sus métodos de intervención y atención. Si bien en México los fenómenos de desplazamiento y 
desapariciones han proliferado durante los últimos años y han representado un reto a atender, donde diversas profesiones encaran nuevos desafíos, renovarse para atender las «nuevas» vulnerabilidades es impostergable. En este sentido, se coincide con Utria et al. (2015) cuando comentan que la psicología de la salud debe esforzarse por facilitar herramientas a las personas que les permitan afrontar situaciones difíciles, potenciar sus habilidades, fortalecer sus cualidades y ayudarlas a encontrar espacios para el desarrollo de sus fortalezas. En esta dirección, consideramos que el trabajo terapéutico debe orientarse a otorgar acompañamiento a las familias durante sus procesos de búsqueda y dejar de forzar los procesos de duelo, que bajo esta realidad no tienen cabida.

En concordancia con los estudios de Romero y Cuellar, 2021; Romero y Gómez, 2020, en los casos de desaparición forzada existen implicaciones complejas que dependen del movimiento y la transformación psíquica que hace el doliente respecto a la imposibilidad de reencuentro; de su capacidad narrativa para resignificar el dolor; de reconocerse como sujeto político social y de derechos, y sobre todo de crear un contexto donde compartir historias que se convierta en un medio sanador para romper con el sufrimiento en silencio. En este estudio, es de destacar que las acciones colectivas y el hecho de pertenecer a grupos y asociaciones de familiares con personas desaparecidas representan para las familias una red de apoyo social fundamental, donde se desarrolla un trabajo psíquico que les permite realizar acciones catárticas, fortalecer vínculos, trabajar emociones, potenciar sus recursos y habilidades.

Cuando las familias se encuentran con otras personas y familias en situaciones similares, se da paso a procesos que permiten una transformación del dolor, ya que este es socializado y reinterpretado, debido en gran parte a que es encauzado a la necesidad de sobreponerse más que al sometimiento del sufrimiento. En palabras de Barudy y Marquebreucq (2006: 36), «el verdadero apoyo terapéutico para estas familias que han sido víctimas de la barbarie humana empieza cuando la familia encuentra, en su nuevo entorno, la solidaridad de otros seres humanos». En este punto, hay que enfatizar que, para fomentar el desarrollo de la resiliencia, deben estar involucrados factores tanto personales como sociales que actúen de manera combinada, por lo que es conveniente considerar que dichos factores respondan a diferentes contextos y circunstancias. Para ello, es necesario discernir y comprender las estrategias de acuerdo con la lógica y la situación de las personas cuando tienen que enfrentarse a situaciones difíciles (García y Domínguez, 2013). Dado lo anterior, se visualiza que las diferentes profesiones tendrían que orientar esfuerzos a caminar con las familias para comprender los nuevos desafíos en concordancia con los diferentes contextos, aprender, transformar y construir con ellas.

Ahora bien, a través del presente estudio, ha sido relevante apreciar que la ausencia o la presencia de redes de apoyo social constituyen un factor importante sobre el sometimiento al sufrimiento o a los procesos de resiliencia. En este sentido, se coincide con Díaz et al. (2015) cuando exponen que las condiciones de precariedad o los escenarios de riesgo por la violencia persistente pueden ser enfrentados de manera más efectiva cuando se cuenta con redes de 
apoyo en el ámbito emocional y social, tanto fuera como dentro de la familia. En concordancia con el estudio de Albarracín y Contreras (2017), bajo entornos adversos donde existe una permanencia de inseguridad y violencia, la generación de procesos de resiliencia es más efectiva cuando se crean espacios para fortalecer vínculos, reconocer y potenciar capacidades.

Dentro de los principales factores que se observaron para propiciar la resiliencia en las familias participantes, se encuentran la existencia de redes de apoyo social entre pares y las alternativas para otorgar nuevos sentidos de vida. En el primero, se observa que el hecho de pertenecer a colectivos de familias que buscan a sus desaparecidos ha significado no solo un apoyo material, sino también emocional, que les otorga contención, comprensión y empatía. De tal forma que la red de apoyo social se hace presente en el interés grupal que reciben las familias cuando se encuentran en una situación en la que requieren ser sostenidos. Además, ser parte activa de los grupos les auxilia a reencauzar su energía a procesos de concertación, de solidaridad, de fortalecimiento, de interacción, lo que les permite ser partícipes, políticos, críticos, y refuerza su sentido de pertenencia e identidad. Con respecto a esto último, recordemos las palabras de Bourdieu: "Los beneficios derivados de la pertenencia a un grupo constituyen, a su vez, el fundamento de la solidaridad que los hace posibles» (Bourdieu, 2000: 148-150). En el segundo, es posible apreciar cómo padecer la desaparición de un ser querido actúa como oxímoron en las familias desplazadas, les permite construir un nuevo sentido de vida a través de orientar gran parte de su existencia a su búsqueda. Al respecto, Cyrulnik ha puntualizado:

...el oxímoron revela el contraste de aquel que, al recibir un gran golpe, se adapta dividiéndose. La parte de la persona que ha recibido el golpe sufre y produce necrosis, mientras que otra parte mejor protegida, aún sana pero más secreta, reúne, con la energía de la desesperación, todo lo que puede seguir dando un poco de felicidad y de sentido a la vida. [...] El oxímoron se vuelve característico de una personalidad herida pero resistente, sufriente pero feliz de esperar a pesar de todo. (Cyrulnik, 2001: 21)

En esta dirección, el desplazamiento de las familias funciona como una tregua ante la violencia e impunidad padecida que les permite concentrarse y organizarse sobre las acciones de búsqueda, las cuales se convierten en un eje medular que facilita su reconstrucción personal y grupal. De esta manera, han encontrado una oportunidad de dar sentido a sobreponerse y encauzar una lucha no solo individual, sino también social, enfocada a las acciones de búsqueda de quienes se encuentran desaparecidos. En este sentido, coincidimos con Durín (2019) cuando señala que el desplazamiento es una manera de resistir a la violencia generalizada, y agregamos: una salvaguarda en medio del desastre que les permite resurgir fortalecidos.

A través de este estudio, se coincide con Hendrick y Denis (2018), pues se observa que existen vínculos entre algunas personas que pueden representar una palanca terapéutica que facilita experiencias de resiliencia colectiva, donde se crean nuevas formas relacionales constructivas y evolutivas. En esta dirección, 
la atención conjunta manifiesta la capacidad de las personas de representarse y compartir intereses comunes y la acción conjunta permite a varios individuos colaborar en un proyecto común. Asimismo, las acciones de solidaridad entre las familias de reproducir la ayuda que en algún momento también ellas recibieron permiten generar la propia resiliencia al incidir sobre procesos resilientes en los otros ${ }^{5}$ f fortalecerse como una red de apoyo social.

De acuerdo con Hopenhayn (2001), la percepción de vulnerabilidad aparece en quienes pueden ser víctimas potenciales de la violencia física. Es de resaltar que, para los participantes del estudio, la exposición a más manifestaciones de violencia es una constante, debido a que las búsquedas de sus familiares son realizadas en gran parte por ellos, y en muchas ocasiones no cuentan con un resguardo de las fuerzas de seguridad pública pertinente. Ellos expresan que el miedo es una constante en sus vidas, y que este se concentra más en el temor fundamentado en las experiencias de que las desapariciones se repitan con más miembros de sus familias. Sin embargo, esto no los paraliza, más bien los obliga a fortalecer las redes de apoyo social no solo entre pares, sino también con instituciones internacionales que puedan ejercer una presión política que facilite su resguardo.

Los participantes reconocen que el miedo y la violencia reducen los apoyos sociales que puedan desarrollarse en la población, sobre todo en aquellos lugares donde se suscitó la desaparición y el desplazamiento. En este punto, concordamos con Ruiz (2006) cuando expone que el miedo a la victimización afecta el tejido social y reduce el capital social. Sin embargo, la organización colectiva de las personas que buscan a familiares desaparecidos ha permitido ponderar las fortalezas grupales y analizar las mejores vías para generar acciones de sensibilización dirigidas a los pobladores que habitan los municipios donde realizan las búsquedas. En este sentido, las reflexiones de Lindón (2008) son relevantes cuando expone que es importante reconocer los miedos en los espacios sociales caracterizados por la violencia, lo cual requiere valorar tanto las implicaciones de las acciones violentas como la cuestión subjetiva que estas producen, ya que, a través de este reconocimiento, las familias dan paso a la creatividad y desarrollan estrategias para generar empatía y recibir apoyo social, sin escatimar la salvaguarda. Al respecto, se encontró afinidad sobre la resiliencia social con las reflexiones de Lamont et al. (2014), pues se observa que las familias de personas desaparecidas, al reconocer y fortalecer sus recursos colectivos, favorecen su empoderamiento, y con ello se incide en una resiliencia social.

Bajo este análisis, se concuerda con Barudy y Marquebreucq (2006), quienes a partir de sus hallazgos encontraron que entre los recursos para hacer frente a los hechos adversos y al estrés se incluye la movilización activa en la búsqueda de información y de apoyo en el tejido social, de esta manera las personas son capaces de gestionar sus problemas y recurrir a la ayuda. Es importante decir que también se encuentra una relación con el estudio de Albarracín y Contreras (2017), quienes han señalado que, bajo escenarios del conflicto

5. En concordancia con Cyrulnik (2014; 2006; 2001). 
armado en Colombia, la transformación de las actividades significativas ocurre a través de estrategias de resiliencia y se vincula con la búsqueda activa de nuevos escenarios de encuentro que faciliten su reconstrucción. Asimismo, se coincide con Granada (2018), quien puntualiza que la resiliencia se produce en los acontecimientos donde las vivencias compartidas generan proximidad, los asuntos individuales se convierten en temas de interés común y, de allí, al politizarse, cuando se movilizan sentimientos de indignación, se convierten en interés público, donde «el para que no se repita» sintetiza la movilización, la indignación, la denuncia y la reclamación.

\section{Conclusiones}

En este estudio se ha ponderado evidenciar que los actos de violencia generados a través de la desaparición de personas y el desplazamiento forzado de sus familias, si bien tienen un poder que desarticula física y psíquicamente, este no es determinante sobre la vida de las personas, al existir la posibilidad resiliente de reconstruirse a través del fortalecimiento de vínculos personales y sociales. Sin embargo, no debemos dejar de evidenciar que esta posibilidad se edifica a través de procesos complejos caracterizados por el dolor, lo que incide sobre los factores que promueven la resiliencia y expone su condición intermitente. Vale la pena puntualizar que no se debe pretender hacer de la resiliencia un sinónimo de bienestar, más bien es preciso reconocer que la resiliencia es una alternativa realista para continuar la vida quebrantada por la violencia.

Las familias que han sido desplazadas ponderan la búsqueda de sus desaparecidos sobre cualquier acción de reconstrucción familiar social en los nuevos espacios de asentamiento. Si bien buscan responder a las necesidades familiares, no enfocan su atención a integrarse socialmente en los nuevos entornos vecinales, más bien dirigen sus esfuerzos a fortalecer las redes de apoyo social entre familias que viven situaciones similares. Asimismo, se observa que, para los integrantes que son proveedores económicos, resolver el ingreso familiar se realiza a través del comercio informal. En algunos casos, cuando deciden integrarse formalmente en el mercado laboral, lo hacen de manera intermitente, de modo que puedan ser parte de las brigadas de búsqueda cuando estas se desarrollen, lo cual incide sobre la certidumbre económica. La atención terapéutica recibida no ha sido apropiada para encauzarse a sus necesidades, pues se ha mostrado limitada y en algunos casos insensible a la incapacidad de vivir un duelo frente a la pérdida ambigua. No obstante, las redes de apoyo social construidas entre pares han sido una palanca terapéutica digna de estudiar con más profundidad para comprender los procesos e incidir sobre su réplica.

Las redes de apoyo social que estas familias construyen y fortalecen les permiten, en primera instancia, sobrellevar la adversidad que las desapariciones y el desplazamiento generan, y en segunda instancia abren posibilidades para procesos de reconstrucción a través del reconocimiento tanto identitario como de fortalezas y habilidades, que facilitan la capacidad de sobreponerse. Asimismo, se visualiza como las redes de apoyo social son un mecanismo base 
no solo para procesos de resiliencia, sino también de empoderamiento, el cual es observado a través de su capacidad de organización, de los conocimientos desarrollados durante las brigadas de búsqueda y de las estrategias encaminadas a promover la empatía social.

No obstante, el hecho de que la resiliencia sea una alternativa relacionada con el empoderamiento no exime a las autoridades en cuestión de procurar la generación de bienestar de sus ciudadanos (Evans y Reid, 2016), lo que debería reflejarse en una mayor eficacia de asistencia, atención, colaboración y acciones orientadas a la justicia restaurativa de estas familias. Se entiende que las implicaciones de una violencia extrema, que proliferó de manera alarmante en poco más de 12 años, no pueden resolverse en poco tiempo y tampoco están libres de complejidades, pero sí existen mecanismos que pueden implementarse bajo constantes análisis de efectividad y en conjunto con quienes tienen más experiencia: las personas y familias que buscan a sus desaparecidos. En este caminar, la academia y la investigación tienen que intensificar esfuerzos, generar más conocimiento, pero también procurar su divulgación y retroalimentación con quienes han sido vulnerados, de forma que se procure una ciencia de incidencia social.

\section{Agradecimientos}

Este estudio fue realizado gracias a la Universidad Nacional Autónoma de México (UNAM), bajo el apoyo del Programa de Becas Posdoctorales en la UNAM, donde fui becaria del Centro Regional de Investigaciones Multidisciplinarias (CRIM) y asesorada por el Dr. Roberto Castro.

Siempre estaré agradecida con nuestra máxima casa de estudios, la UNAM, por ser parte de mi identidad, de mi formación y por ser sede para la generación de ciencia de incidencia social. Doy las gracias a la Coordinación de Humanidades de la UNAM por creer en este trabajo. Dedico un agradecimiento al Dr. Roberto Castro y al CRIM por su apertura y apoyo.

Asimismo, agradezco a la Universidad Autónoma de Tamaulipas la posibilidad que ha abierto para dar continuidad a mi labor científica.

\section{Referencias bibliográficas}

Albarracín, L. A. y Contreras, K. A. (2017). «La fuerza de las mujeres: un estudio de las estrategias de resiliencia y la transformación en la ocupación humana de mujeres víctimas del conflicto armado en Colombia». Revista Ocupación Humana, 17 (1), 25-38. $<$ https://doi.org/10.25214/25907816.154>

Almanza, A. M.; Hernández, R. y Gómez, A. H. (2020). «Pérdida ambigua: madres de personas desaparecidas en Tamaulipas, México». Revista Región y Sociedad, 32, 1-21. <https://doi.org/10.22198/rys2020/32/1396>

Amar, J.; Kotliarenco, M. y Abello, R. (2003). «Factores psicosociales asociados con la resiliencia en niños colombianos víctimas de violencia intrafamiliar». Revista Investigación y Desarrollo, 11 (1), 162-197. 
Barudy, J. y MarquebreucQ, A.-P. (2006). Hijas e hijos de madres resilientes. Traumas infantiles en situaciones extremas: violencia de género, guerra, genocidio, persecución y exilio. Barcelona: Gedisa.

Bezanilla, J. M. y Miranda, A. (2014). «Violaciones graves a derechos humanos y su impacto familiar». Revista Cuadernos de Crisis, 2 (15), 1-9.

BourdieU, P. (2000). «Las formas del capital. Capital económico, capital cultural y capital social». En: Bourdieu, P. Poder, derecho y clases sociales. Barcelona: Desclée.

Cabodevilla, I. (2007). "Las pérdidas y sus duelos». Revista Anales del Sistema Sanitario de Navarra, 3 (30), 163-176.

<https://doi.org/10.4321/S1137-66272007000600012>

CAmpo, A. y Herazo, E. (2014). «Estigma y salud mental en víctimas del conflicto armado interno colombiano en situación de desplazamiento forzado». Revista Colombiana de Psiquiatría, 43 (4), 212-217. <https://doi.org/10.1016/j.rcp.2014.09.004>

Clemente, M. A. (2003). «Redes sociales de apoyo en relación al proceso de envejecimiento humano». Interdisciplinaria, 20 (1), 31-60.

ConchA, A. (2002). "Impacto social y económico de la violencia en las Américas». Revista Biomédica (22), 347-361. <https://doi.org/10.7705/biomedica.v22iSupp2.1185>

CyrulniK, B. (2001). La maravilla del dolor. Barcelona: Gedisa.

- (2006). El amor que nos cura. Barcelona: Gedisa.

- (2014). "La resiliencia en el siglo XXI». En: MADARIAGA, J. M. (coord.). Nuevas miradas sobre la resiliencia. Ampliando ámbitos y prácticas. Barcelona: Gedisa.

DELGADO, R. (2014). «Elaboración del duelo de una madre cuyo hijo trabajaba como sicario en Ciudad Juárez, Chihuahua». Revista Noesis, 23 (46), 224-244. <https://doi.org/10.20983/noesis.2014.2.8>

DíAz, M. C. y Romo, R. (2019). La violencia como causa de desplazamiento interno forzado. Aproximaciones a su análisis en México. Ciudad de México: CONAPO.

Díaz, V.; Molina, A. y Marín, M. (2015). «Las pérdidas y los duelos en personas afectadas por el desplazamiento forzado». Revista Pensamiento Psicológico, 13 (1), 65-80. <https://doi.org/10.11144/Javerianacali.PPSI13-1.pdpa>

Durín, S. (2019). ¡Sálvese quien pueda! Violencia generalizada y desplazamiento forzado en el noreste de México. Ciudad de México: CIESAS.

Evans, B. y REID, J. (2016). Una vida en resiliencia. El arte de vivir en peligro. Ciudad de México: Fondo de Cultura Económica.

Ferreira, M.; Nunes, M.; ReIS, G.; Morraye, M. y Rocha, S. (2012). «Social support, socioeconomic and clinical risk: Comparison between to neighborhoods in a Brazilian up country town». Revista da Escola de Enfermagem da USP, 46 (4), 822-828. <https://doi.org/10.1590/S0080-62342012000400006>

Gallar, M. (2006). Promoción de la salud y apoyo psicológico al paciente. Madrid: Thomson K Paraninfo.

Gallardo, M. y SABAN, K. (2021). «Búsquedas estéticas para el afecto y la desafección. La memoria de hijos de sobrevivientes y desaparecidos en Chile y Argentina». Acta Poética, 42 (1), 13-42. <https://doi.org/10.19130/iifl.ap.2021.1.883>

García, M. y Domínguez, E. (2013). «Desarrollo teórico de la resiliencia y su aplicación en situaciones adversas: una revisión analítica». Revista Latinoamérica de Ciencias Sociales, Niñez y Juventud, 11 (1), 63-77. 
Gatti, G. (2011). Identidades desaparecidas. Peleas por el sentido en los mundos de la desaparición forzada. Buenos Aires: Prometeo Libros.

Gómez, E. y Kotllarenco, M. (2010). «Resiliencia familiar: un enfoque de investigación e intervención con familias multiproblemáticas». Revista de Psicología, 19 (2), 103-132. <https://doi.org/10.5354/0719-0581.2010.17112>

GONZÁLEZ, C. (2004). "Transformación y resiliencia en familias desplazadas por la violencia hacia Bogotá». Revista de Estudios Sociales (18), 123-130. <https://doi.org/10.1016/S2007-4719(13)70944-X>

GonZÁlEZ-Arratia, N. I. y VAldEZ, J. L. (2013). «Resiliencia. Diferencias por edad en hombres y mujeres mexicanos». Acta de Investigación Psicológica, 3 (1), 941-955.

GranADA, P. (2018). «La resiliencia comunitaria como expresión de la inteligencia colectiva. La capacidad re-generativa de los colectivos humanos en las prácticas de protección de la infancia en contextos de adversidad». En: SiMPSON, M.; MunisT, M.; Cruz, E.; Kotliarenco, M.; Klasse, E. y Melillo, A. Resiliencia comunitaria. Buenos Aires: Dunken.

GuTiÉRREZ, J. (2016). «Los derechos de las niñas y niños huérfanos por situación de violencia: víctimas de la guerra en la frontera norte de México». Revista Internacional de Derechos Humanos, 6, 33-51.

HENDRICK, S. y DENIS, J. (2018). «Familias, psicosis, institución y corresiliencia». En: CYRULNIK, B. y ANAUT, M. (coords). Resiliencia y adaptación. La familia y la escuela como tutores de resiliencia. Barcelona: Gedisa.

HOPENHAYN, M. (2001). La vulnerabilidad reinterpretada: asimetrías, cruces y fantasmas. Santiago de Chile: Documento de Trabajo-División de Desarrollo Social/ CEPAL. <https://doi.org/10.18356/6447064a-es>

Hoyos, D. y NieTO, A. (2016). «Procesos organizativos de mujeres víctimas del conflicto armado y sus relaciones con la democracia local en el Oriente Antioqueño». Revista Desafios, 29 (1), 139-175. $<$ https://doi.org/10.12804/revistas.urosario.edu.co/desafios/a.4484>

Klinkert, M. de (2003). Resiliencia: la estimulación para enfrentar desafíos. Buenos Aires: Lumen.

Kotllarenco, M.; CÁCeres, I. y Fontecilla, M. (1997). Estado de arte en resiliencia. Washington: Organización Panamericana de la Salud.

LAmOnT, M.; WelbuRn, J. y Fleming, C. (2014). «Respuestas a la discriminación y resiliencia social bajo el neoliberalismo: los Estados Unidos comparados». Cátedra Norbert Lechner. Disponible en <http://www.catedranorbertlechner.udp.cl/wp-content/uploads/2016/04/LamontWelburn-y-Fleming-2012.pdf>.

LASTRA, M. S. (2019). “Dejar de ser síntoma con el silencio”: la inscripción del exilioretorno en el campo de la salud mental en la posdictadura argentina (1983-1986)». Revista Tempo, 25 (2).

<https://doi.org/10.1590/TEM-1980-542X2018v250211>

Lavretsky, H. (2014). Resilience and Aging: Research and Practice. Baltimore: Johns Hopkins University Press.

Lindón, A. (2008). «Violencia/miedo, espacialidades y ciudad». Revista Casa del Tiempo, $1(4), 8-15$.

López, O. L. (2005). «La resiliencia de las familias afectadas por el desplazamiento forzado en Colombia». Revista Perspectivas Sociales, 7 (2), 1-28. 
MARINIS, N. (2017). «Despojo, materialidad y afectos: la experiencia del desplazamiento forzado entre mujeres Triquis». Revista Desacatos, 53, 98-113.

Masten, A. (2001). "Ordinary magic: Resilience processes in development». American Psychologist, 56 (3), 227-238. <https://doi.org/10.1037/0003-066X.56.3.227>

MERCADO, J. (2013). «La perspectiva de género en el estudio de las mujeres en condición de desplazamiento». En: TORRENS, O. (coord.). El desplazamiento interno forzado en México. Un acercamiento para su reflexión y análisis. México: Centro de Investigaciones y Estudios Superiores en Antropología Social / LXII Legislatura del Senado de la República / El Colegio de Sonora, 113-154.

- (2016). «El desplazamiento interno forzado en México». El Cotidiano, 200, 181-192. Disponible en <https://www.redalyc.org/ARTICULO.OA?ID=325486300016>.

- (2018). "Dossier. La violencia y el desplazamiento interno forzado en México». Cuicuilco Revista de Ciencias Antropológicas, 25 (73), 9-18.

Miranda, J. L. E. (2000). "Psicología y violencia». En: Ramos, C. Violencia en una sociedad en transición: ensayos. San Salvador: PNUD, 49-74.

Monroy, B. y Palacios, L. (2011). «Resiliencia. ¿Es posible medirla e influir en ella?». Revista Salud Mental, 34 (3), 237-246.

Morina, N.; AKhtar, A.; BARTh, J. y Schnyder, U. (2018). «Psychiatric Disorders in Refugees and Internally Displaced Persons After Forced Displacement: A Systematic Review». Frontiers in Psychiatry, 9, 2-15. <https://doi.org/10.3389/fpsyt.2018.00433>

PALACIO, J. y MADARIAGA, C. (2006). «Lazos predominantes en las redes sociales personales de desplazados por violencia política». Revista Investigación y Desarrollo, 14 (1), 86-119.

Puelles, M. C. (2018). "Afrontamiento resiliente de la desaparición de un ser querido. Psicopatología Clínica, Legal y Forense (18), 151-175.

Rodríguez, J.; Torre, A. de la y Miranda, C. (2002). «La salud mental en situaciones de conflicto armado». Revista Biomédica, 22, 337-346. <https://doi.org/10.7705/biomedica.v22iSupp2.1183>

Romero, L. C. y Cuellar, V. K. (2021). «Impactos psicosociales en familiares víctimas de desaparición forzada». Revista Reflexiones, 101 (1), 1-9. <https://doi.org/10.15517/rr.v101i1.44198>

Romero, L. C. y Gómez. J. S. (2020). «Elaboración del duelo en familiares de las víctimas de desaparición forzada en el departamento del Caquetá». Inclusión y Desarrollo, 8 (1), 117-130. <https://doi.org/10.26620/uniminuto.inclusion.8.1.2021.117-130>

RuBio, L. (2014). Desplazamiento interno inducido por la violencia. Una experiencia global, una realidad mexicana. México: Instituto Tecnológico Autónomo de México / Comisión Mexicana de Defensa y Promoción de los Derechos Humanos (CMDPDH).

RuIZ, J. (2006). «Cultura ciudadana, miedo al crimen y victimización: un análisis de sus interrelaciones desde la perspectiva del tejido social». Revista Acta Colombiana de Psicología, 10 (1), 64-74.

SalazAr, L. y Álvarez, J. (2018). "Violencia y desplazamientos forzados en México». Revista de Ciencias Antropológicas, 25 (73), 19-38.

SAlazAr, K. y CASTRO, R. (2020). «Mujeres que caminan a través de la adversidad. La posibilidad resiliente frente a casos violentos complejos vinculados con las desapariciones en México». OBETS. Revista de Ciencias Sociales, 15 (2), 711-746. <https://doi.org/10.14198/OBETS2020.15.2.12> 
- (2021). «Nuestras hijas no volvieron a casa. Caminos de reconstrucción de mujeres que buscan mujeres desaparecidas». Via Iuris, 30, 1-35. <https://doi.org/10.37511/viaiuris.n30a7>

SÁnchez, D.; Castaño, G. A. y Sierra, G. M. (2019). «Salud mental de los adolescentes y jóvenes víctimas de desplazamiento forzado en Colombia». CES Psicología, $12(3), 1-19$.

<https://doi.org/10.21615/cesp.12.3.1>

Schlaudt, V.; Bosson, R.; Williams, M.; German, B.; Hooper, L.; Frazier, V.; CARrico, R. y Ramirez, J. (2020). "Traumatic Experiences and Mental Health Risk for Refugees». International Journal Environmental Research Public Health, 17 (6), 1-10. <https://doi.org/10.3390/ijerph17061943>.

Scoloveno, R. (2017). "Measures of resilience and an evaluation of the Resilience Scale (RS)». International Journal Emergency Mental Health and Human Resilience, 19 (4), 1-7.

Sierra, Y. C.; PAlacio, J. E.; Madariaga, C. y Ávila, J. H. (2019). «Redes personales de apoyo entre víctimas, desmovilizados y comunidad receptora». Revista Hispana para el Análisis de Redes Sociales, 30 (1), 43-53. $<$ https://doi.org/10.5565/rev/redes.793>

SLUZKI, C. (1998). La red social. Frontera de la práctica sistémica. Barcelona: Gedisa.

Stornaiuolo, M.; Chauca, R. L. y BaCA, N. (2007). «Acompañamiento psicosocial en procesos de investigación antropológica forense en Perú». En: PÉREZ, P. y Navarro, S. Resistencias contra el olvido. Barcelona: Gedisa.

Thотs, P. (1985). «Social support as coping assistance». Journal of Consulting and Clinical Psychology, 4, 416-423. <https://doi.org/10.1037/0022-006X.54.4.416>

TORralBA, L. M. (2013). La personalidad resiliente. Madrid: Síntesis.

Trejo, G. y Ley, S. (2016). «Federalismo, drogas y violencia. Por qué el conflicto partidista intergubernamental estimuló la violencia del narcotráfico en México». Revista Política y Gobierno, 23 (1), 11-56.

Utria, L.; Amar, J.; Martínez, M.; Colmenares, G. y Crespo, F. (2015). Resiliencia en mujeres víctimas del desplazamiento forzado. Barranquilla: Universidad del Norte.

VEGA, M. (2020). «Impacto psicológico y salud mental en la población refugiada. Una mirada desde el Enfoque Integrativo Supraparadigmático (EIS)». Actualizaciones en Psicoterapia Integrativa, XI, 6-25.

VelázqueZ, A. (2016). «La realidad de las personas desplazadas por la violencia en México. Comisión de Derechos Humanos del Distrito Federal». Revista Dfensor (4), 45-49.

- (2017) Desplazamiento interno por violencia en México. Causas, consecuencias y responsabilidades del Estado. Disponible en <https://archivos.juridicas.unam.mx/www/bjv/libros/11/5197/1.pdf>.

Venturoli, S. (2009). «Huir de la violencia y construir. Mujeres y desplazamiento por violencia política en Perú». Rivista Telemática di Studi sulla Memoria Feminile, DEP, 11, 46-63.

Villalba, C. (2003). «El concepto de resiliencia individual y familiar. Aplicaciones en la intervención social». Revista Intervención Psicosocial, 12 (3), 283-299 


\section{Páginas electrónicas}

Comisión Mexicana de Defensa y Promoción de los Derechos Humanos (2019). «Episodios de desplazamiento interno forzado masivo en México». Disponible en

<http://www.cmdpdh.org/publicaciones-pdf/cmdpdh-episodios-desplazamientointerno-forzado-masivo-en-mexico-informe-2019.pdf $>$.

SeCRETARÍA de Gobernación (2020). «A nombre del Estado mexicano, el subsecretario Alejandro Encinas Rodríguez, ofrece disculpas por desapariciones forzadas». Boletin de Prensa $n .^{\circ}$ 515/2020. Disponible en

<https://www.gob.mx/segob/prensa/a-nombre-del-estado-mexicano-el-subsecretario-alejandro-encinas-rodriguez-ofrece-disculpas-publicas-por-desaparicionesforzadas $>$. 
